\title{
Opportunities for ethnographic methodologies in B2B service research
}

\begin{abstract}
Purpose - To highlight the suitability, application, and fruitful opportunities for ethnographic methodologies in contemporary B2B service research

Design/methodology/approach - Literature review and conceptual analysis of ethnographic research methodology and B2B service literatures

Findings - This paper highlights the central features of ethnographic research methodologies, their key differences to other qualitative methodologies, key trends in contemporary B2B service research, and opportunities for ethnographic research methodologies in selected priority areas Research limitations/implications - This paper highlights the opportunities, unique strengths, and specific advantages of ethnographic research methodologies to advance B2B service research and theory development

Practical implications - This paper encourages B2B firms to undertake ethnographic field projects to better understand customers' roles, experiences, and usage processes during complex B2B service deliveries

Originality/value - Ethnographic research approaches have been largely overlooked or neglected in B2B service research. This paper highlights their potential, suggests areas for application, and encourages B2B service researchers to adopt ethnographic approaches to delve deeper into the social and cultural space involved in complex B2B services
\end{abstract}

Keywords Ethnography, B2B Services, Qualitative Research, Participant Observation, Lived Experiences

Paper type - Conceptual paper 


\section{Introduction}

Service research is expanding at a rapid pace, and becoming an increasingly interdisciplinary field and overarching analytical lens to analyze a wide variety of issues in the global market space (Gustafsson et al., 2016; Lusch et al., 2016). Both scholars and practitioners have fostered this development by outlining impactful service research priorities (Oström et al., 2010; 2015), enhanced theory development opportunities (Brodie and Gustafsson, 2016), and roadmaps for future service research (Keating et al., 2018). Yet, to help researchers to also capture the increasingly rich and complex service experiences in the contemporary economy (Jaakkola et al., 2015), there is a growing need to adopt research methodologies that can capture the increasingly dynamic and holistic service phenomena that unfold through cultural, social, temporal, and spatial spectrums (McColl-Kennedy et al., 2015; Sharma et al., 2018). One such methodology - often overlooked but no less potent - is ethnographic research.

Ethnographic research methods offer "unique means to understand market realities", and they have been a staple and invaluable tool in the consumer marketers' toolbox for decades (Arnould; Wallendorf, 1994; Cayla and Arnould, 2006, p. 1). Yet, their role in B2B marketing research has been significantly less pronounced, if not scant (Visconti, 2010; Pressey et al., 2014), particularly in service marketing and management (von Koskull., 2014). This is surprising, given that the unique strength of ethnography is to elicit deep and naturally occurring insights on the lived experiences and socio-cultural practices of consumption, usage, and interpersonal interaction (Pettigrew, 2000), which are arguably some of the defining characteristics of B2B services (Zolkiewski et al., 2018). While several B2B scholars have pointed out the need for more ethnographic research (e.g., Visconti, 2010; Hoholm and Araujo, 2011; La Rocca et al., 2017), it seems that the "ethnographic turn" that has invigorated recent consumer and management research (Rouleau et al., 2014) is still long way from making it in the contemporary B2B service domain.

Consequently, to address these calls and propel the current B2B service research forward, the purpose of this article is to i) highlight the central features of ethnographic research methodologies with their unique strengths and advantages, ii) illustrate their key differences to other, allegedly more mainstream qualitative methodologies, and iii) highlight key trends in B2B service research that could provide fruitful opportunities for ethnographic research approaches. Overall, this, article contributes to contemporary service research by offering a fresh perspective (McColl-Kennedy et al., 2015) on a less used but powerful qualitative methodology, which can provide unique advantages and novel viewpoints for theorization in the increasingly important and expanding B2B service domain (Brodie and Gustafsson, 2015; Oström et al., 2015).

The remainder of this article is structured as follows. First, we discuss the central features of ethnographic research methodologies, and highlight their key differences to other qualitative methodologies. Second, we highlight key trends in B2B service research, and suggest how ethnographic approaches could help to reveal new or deeper insights on key issues. Finally, we discuss the conclusions, and potential implications for research and practice. 


\section{Primer on ethnographic research methodologies}

This section offers a brief overview of the key features of ethnographic research methodologies. Given that there are several textbooks which explain how ethnographic studies should be conducted (e.g., van Maanen, 1988; Hammersley and Atkinson, 2007; Fetterman, 2009), and several forms of ethnographic approaches ${ }^{1}$ that are subtly different in their philosophical and/or methodological designs (Koro-Ljungberg and Greckhamer, 2005; Arnould and Price, 2006; Rouleau et al., 2014), the purpose of this article is not to unpack and analyze these in detail. Instead, our goal is to outline the central features of ethnographic research methodology in terms of focus, methods, and data, and illustrate their key differences to other qualitative methodologies.

\section{Central features of ethnographic research methodology}

In terms of focus, the key goal of ethnographic research methodology is to elicit rich insights about actors' lived experiences that occur in a natural context and within specific cultural or social groups (Rouleau et al., 2014). In other words, ethnography aims to understand and depict reality as it is actually lived and experienced in action - and not necessarily told or made sense of afterwards by native participants in organic and real-life settings (Hammersley and Atkinson, 2007). This helps researchers to unpack how culture, as represented by shared beliefs, values, norms, and attitudes (van Maanen, 2006), drives or hinders organizational or individual action (Goulding, 2005), and constructs meanings for specific, culturally or socially grouped communities or other stakeholders (Atkinson, 2015).

In terms of methods, the hallmark of ethnographic research methodology is participant observation (Hammersley and Atkinson, 2007), which allows researchers to spend extended periods in the field, either as or with the members of the studied groups "in situ" (van Maanen, 1988), and "see the world through the eyes of the members of the culture being examined" (Goulding, 2005). The participant observation can range from active to passive, overt to covert, and inside to outside, with each mode offering subtle yet distinct trade-offs in terms of intensity and duration, as well as access and opportunities for engagement (Zilber, 2014; Strudwick, 2018). Essentially, the extended immersion and prolonged engagement in the field help capture more spontaneous, naturally occurring activities and behaviors, as well as informal discussions and other daily events and rituals that may at first sight seem mundane, but help to generate a deeper and more holistic account of the complex and intricate ways culture influences organizational life (Hammersley and Atkinson, 2007; Cunliffe, 2010).

In terms of empirical data, ethnographic research methodology relies on the prominent use of rich and versatile data from multiple sources (Atkinson, 2015), including (but not limited to) field observations, interviews, verbal recordings, video tapes, photographs, documents, research diaries, and field notes (Arnould and Wallendorf, 1994). The richness and versatility of the ethnographic data play a key role in teasing out the "densely textured", "vivid", and "nuanced" behaviors, routines, rituals, and other social interactions that emerge as a result of local rules and cultural meanings (Katz, 2001; Cunliffe, 2010). While documenting verbal accounts and language-in-use (i.e., specific jargon, dialects, special words) are important in ethnography (Elliot and Jankel-

\footnotetext{
${ }^{1}$ For example, Hammersley (2013) distinguishes between theoretical, critical, policy, and practitioner ethnography; Koro-Ljungberg \& Greckhamer between naturalist, interpretative, critical/feminist, and deconstructive ethnography; and Arnould \& Price (2006) between macro-, meso-, and micro-level ethnography.
} 
Elliot, 2003), equal, if not greater, weight is given to accessing and analyzing places, spaces, locations, events, symbols, and other artefacts that convey social and cultural meanings and/or broader institutions (Mannay and Morgan, 2014; Atkinson, 2015). Interviews, in turn, are usually (but not always) informal and spontaneous in nature, and occur on the spot, in-situ, and more often as free-flowing and informant-controlled than structured and researcher-led conversations (von Koskull, 2014).

\section{Key differences between ethnographic and other qualitative research methodologies}

The key difference between ethnographic and other forms of qualitative research methodologies is that ethnography aims to capture naturally occurring behaviors in-flight, in real-time, and as they unfold in reality (Pettigrew, 2000), while case studies and grounded theories, for example, usually aim to document retrospective accounts of past experiences and/or behaviors that are recalled, and hence filtered, and potentially biased, or even perverted by the informants own interpretations and mental schemata (Borghini et al., 2010). Furthermore, ethnographic studies always include some form of participant observation, involving deep and long-lasting immersion and engagement in the field and in situ, while most other qualitative approaches appreciate observation, but ultimately treat it as secondary, and are usually satisfied with limited to no immersion and field time, and sporadic and/or isolated engagement with critical events (e.g., Corbin and Straus, 2015; Yin, 2016). Finally, ethnographic studies give primacy to multimodal data sets from different sources to convey the rich and nuanced complexities of everyday life, whereas many other qualitative methodologies tend to rely primarily on relatively isolated and single forms or sources of data, such as interviews, focus groups, or document analyses (Atkinson, 2015). Table 1 provides an expanded summary of the typical differences between ethnographic and other qualitative research methodologies.

Table 1. Illustrative overview of the key differences between ethnographic and other qualitative research methodologies

\begin{tabular}{|l|l|l|}
\hline Key features & Ethnographic research methodologies & $\begin{array}{l}\text { Other qualitative research methodologies } \\
\text { (i.e., case studies, grounded theory) }\end{array}$ \\
\hline & \multicolumn{2}{|c|}{ In terms of research focus } \\
\hline Key focus & Lived experiences & Recalled experiences \\
\hline & Observed practices & Enacted practices \\
\hline & Cultural/social behavior & Organizational/individual behavior \\
\hline Context & Day-to-day activities, daily events & Strategic activities, critical events \\
\hline & Natural setting & Formal setting \\
\hline & Particular and local setting & Generic and transferable setting \\
\hline & Subjective and situated account & Objective and abstract account \\
\hline Focal actors & Embedded in context & Isolated from context \\
\hline Key features & Cultural or social groups/actors & Organizational or individual actors \\
\hline & Ethnographic research methodologies & $\begin{array}{l}\text { Other qualitative research methodologies } \\
\text { (i.e., case studies, grounded theory) }\end{array}$ \\
\hline Observation & \multicolumn{2}{|c|}{ In terms of research methods } \\
\hline Perspective & Participant observation & Non-participant/no observation \\
\hline $\begin{array}{l}\text { Nature and intensity } \\
\text { of field engagement }\end{array}$ & Emic/insider perspective & $\begin{array}{l}\text { Extended immersion, } \\
\text { long time in the field }\end{array}$ \\
\hline & Focus on ongoing events & $\begin{array}{l}\text { Limited immersion, } \\
\text { short/no time in the field }\end{array}$ \\
\hline & Prolonged (engagement) & Focus on isolated events \\
\hline
\end{tabular}




\begin{tabular}{|l|l|l|}
\hline Key features & Ethnographic research methodologies & $\begin{array}{l}\text { Other qualitative research methodologies } \\
\text { (i.e., case studies, grounded theory) }\end{array}$ \\
\hline & \multicolumn{2}{|c|}{ In terms of data collection } \\
\hline Nature of data & Multimodal, multi-source & Interviews-based, single-source \\
\hline & Experience-near & Experience-far \\
\hline Gives primacy to & Tacit & Verbal \\
\hline Nature of interviews & Emervational data & Interview data \\
\hline & In-situ, on-site, on the spot & Planned, formal \\
\hline & Life history/daily routine & Non-situ, off-site, after key events \\
\hline Key goal/outcome & Cultural/social framework & Thematic \\
\hline
\end{tabular}

*Naturally, all the other qualitative research methodologies have their own nuances and distinct details, but for illustrative purposes, they are condensed and generalized together here to highlight the typical key differences between ethnographic and other qualitative research methodologies.

\section{Key trends in B2B service research and opportunities for ethnographic inquiries}

In the contemporary B2B space, services are increasingly considered as interactive, collaborative and dynamic processes that unfold in complex service networks and broader ecosystems across time and space, and deliver outcomes and experiences that aim to improve diverse stakeholders' life and well-being, well beyond economic attributes alone (Jaakkola and Alexander, 2014; McColl-Kennedy et al., 2015; Zolkiewski et al., 2018). While the shift from products to services, and the accompanying key trends and priorities that have driven the B2B "service revolution" are well-recognized in the current literature (e.g., Oström et al., 2010; 2015; Kowalkowski et al., 2017), they have been addressed mostly with mainstream B2B research methodologies such as case studies and surveys (cf., Easton, 2010; Woodside, 2010), which tend to emphasize retrospective and static analyses conducted at single points in time, and filtered through several layers of interpretation (Borghini et al., 2010). This inevitably leaves some blind spots and underexplored areas in the current literature, which, if addressed, could provide "fresh perspectives" for B2B service research (McColl-Kennedy et al., 2015). Against this background, we highlight five key trends in B2B service research that could benefit from ethnographic inquiry.

\section{Service actors and their roles}

First, the majority of extant service research still conceptualizes service or "servitized" offerings in the B2B space, primarily in terms of (underlying) product-service combinations (cf., Tuli et al., 2007; Brax and Visintin, 2017), but pays less attention to the conceptualizations of actors' social and cultural roles, as well as their related value-in-use goals in B2B service delivery (Macdonald et al., 2016; Prior, 2016; Prior et al., 2019). Consequently, recent research has highlighted the need for a better understanding of how to conceptualize relevant actor groups, and in particular, their "cognitive and cultural value-based understanding" in B2B service deliveries (Kleinaltenkamp et al., 2017, p. 732; Huber and Kleinaltenkamp, 2019).

Ethnographic research approaches could help to shed light on how actors' self- and groupperceived roles evolve or mutate during complex B2B service deliveries, in both vendor and buyer organizations; and on what kind of social and/or cultural dynamics influence self-, group-, and interorganizational-level appraisals of expected role-related activities, behaviors, and value-in-use goals. For example, researchers could stay embedded, overtly or covertly, in vendor and/or buyer organizations during complex and lengthy service implementation processes, and observe how and 
why actors adopt or reject new roles and behaviors, and what kind of ramifications this has for both current and subsequent service deliveries in both organizations. Or researchers could compare how contractually-specified (formal) and offering-related role requirements differ from socially or culturally expected (informal) role requirements, and what kind of impacts (mis)aligned role requirements and expectations may have on service deliveries.

\section{Social and cultural changes in service delivery}

Second, while a host of service studies have examined the strategic, operational, and tactical changes required to deliver B2B services successfully (e.g., Ulaga and Reinartz, 2011; Cusumano et al., 2015), understanding the cultural and social changes that come with the move towards a higher B2B service component remains a critically under-explored priority area (Oström et al., 2010; Ulaga, 2018). Consequently, many scholars have called for more insights into the social and psychological factors that drive or hinder the adoption of B2B service culture, and on how to garner buy-in and mental commitment from employees and customers to support service-led operations (Ulaga and Loveland, 2014; Töytäri et al., 2017).

Ethnographic research approaches could help to go beyond the surface-level view of offering and strategy-level changes, and provide a deeper and more nuanced insight into more intangible and socially layered changes; such as how, why, and under what conditions do cultural, political, psychological, and/or symbolic factors drive the success or failure of B2B service deliveries. For example, researchers could employ multimodal data to investigate what kind of communication strategies, boundary objects, artefacts, and other symbols managers in both vendor and buyer organizations employ, to change deeply held values, beliefs, and assumptions, and employ participant observation to investigate the subsequent effects on employees in both organizations.

\section{Customer engagement}

Customer engagement $(\mathrm{CE})$ has been one of the fastest growing priority areas in the contemporary service research (Jaakkola et al., 2018; Brodie et al., 2019). CE is broadly defined as a customer's psychological, cognitive, and/or emotional state that results from interactions with a focal firm or brand, and manifests as social and cultural behaviors towards a focal firm or broader service system (van Doorn et al., 2010; Brodie et al., 2011; Jaakkola and Alexander, 2014). However, while there is rich and an emerging body of research on CE, most of it is either conceptual or predominantly focused on B2C service settings. Consequently, several scholars have highlighted the pressing need for empirical studies in B2B service settings, where the intensity, rationality, and multi-actor nature of service processes are likely to have a pronounced effect on CE (e.g., Vivek et al., 2016; Reinartz and Berkmann, 2018).

Ethnographic research approaches could provide unique means to understand and capture how and why CE manifests at individual and organizational levels, whether there are any organizational or institutional characteristics that inhibit (or amplify) some individual-level CE behaviors, and under what conditions are CE behaviors at both levels (mis)aligned, and to what effect. For example, researchers could employ various forms of participant observation or prolonged field engagement, to investigate how and why individuals might change or adapt their CE behaviors when acting individually or in groups, or how different social and cultural group dynamics might alter CE behaviors over time. Furthermore, multimodal datasets could provide deeper insights into more 
sensitive topics, such as how latent or tacit social drivers and cultural inhibitors may influence CE in formal and informal settings.

\section{Customer experiences and service journeys}

Fourth, an emerging area in the B2B service context is customer experiences (Jaakkola et al., 2015; McColl-Kennedy et al., 2015), defined as “customer's cognitive, emotional, behavioral, sensorial, and social responses to a firm's offerings during the customer's entire purchase journey" (Lemon and Verhoef, 2016, p. 71). While customer experiences are dynamic, multi-dimensional, and shaped by multiple subsequent encounters, most of the present studies explore them with singlemethods studies, retrospective interviews, and static surveys that focus on recalled - but not necessarily lived - experiences (McColl-Kennedy et al., 2015). Consequently, there is a strong need to adopt multiple methods and longitudinal approaches that are able to capture all of the many facets of customer experiences simultaneously, and reveal the rich and complex empirical realities that unfold along different types of service journey (Lemon and Verhoef, 2016; Zolkiewski et al., 2018).

Especially in the B2B service context, ethnographic research approaches could provide unique possibilities to understand and reveal how customers - either as individuals or (in)formal members of buying and usage groups - perceive the protracted and multi-stakeholder B2B service implementation cycles; and, how the intra- and inter-organizational social and cultural group dynamics can alter customer experiences (cf., Macdonald et al., 2016; Kleinaltenkamp et al., 2017). For example, researchers could employ participant observation or immersive shadowing techniques to reveal and map all the touchpoints for different customer actors before, during and after the service delivery. They could also employ multimodal data collection methods to capture both visible and latent, as well as immediate and delayed responses to the service delivered. Furthermore, deep participant observation could also help to track when and how individual and buying or usage group members' journeys intertwine, and uncover the differences and interdependencies between individually and collectively experienced customer journeys.

\section{Connected technologies and smart services}

Finally, advanced technology, intelligent products, robotics, and "smart services" have been one of the most pervasive forces shaping the B2B service field during the last decade (Oström et al., 2010; Wunderlich et al., 2015; van Doorn et al., 2017; Wirtz et al., 2018). But while technologyenhanced services allow vendors to understand, access, and ultimately serve their customers better, a majority of B2B service research in this area has focused on either the things new service technologies can do (Porter and Heppelman, 2014; Huang and Rust, 2018) or customers' beliefs and perceptions of them (Wunderlich et al., 2012), rather than on their effects and the ramifications for social and cultural agents, which can be dramatic (cf., Čaić et al., 2017; Kunz et al., 2019). Hence, there is a strong need to understand how connected technologies and smart services transform social agents "livesworlds", and how advanced service technologies will change social and cultural behaviors (Oström et al., 2015; Wirtz et al., 2018).

Ethnographic research approaches could help to provide a more holistic picture of the role different service technologies play in both employees' and customers' daily lives, how and why they are utilized (or not) at different stages in the service delivery process, and what their impacts are on 
social and cultural interactions. For example, researchers could employ participatory and immersive methods to gain a deeper understanding of how and why social actors employ service technologies during their daily activities; how this changes their behaviors and interactions with other actors; and, how and under what conditions do specific service technologies add or detract to and from customer experiences. Table 2 summarizes the key trends and potential opportunities offered by ethnographic research.

Table 2. Key trends in B2B service research and opportunities for ethnographic inquiries

\begin{tabular}{|c|c|}
\hline Key B2B service trends & Opportunities for ethnographic inquiries to: \\
\hline Service actors and roles & $\begin{array}{l}\text { - Conceptualize relevant actor groups, and their cognitive and cultural value-based } \\
\text { - Understanding in B2B service deliveries } \\
\text { - Understand how actors' self- and group-perceived roles evolve or mutate during } \\
\text { complex B2B service deliveries, in both vendor and buyer organizations } \\
\text { - Identify what kind of social or cultural dynamics influence self-, group-, and } \\
\text { interorganizational-level appraisals of B2B service deliveries } \\
\text { - Capture how and why actors adopt or reject new roles and behaviors, and what } \\
\text { kind of ramifications this has for both current and future service deliveries } \\
\text { - Understand how contractually specified role requirements differ from socially or } \\
\text { culturally expected role requirements } \\
\text { - Identify what kind of impacts (mis)aligned role requirements and expectations may } \\
\text { have on service deliveries }\end{array}$ \\
\hline $\begin{array}{lrr}\text { Social } & \text { and } & \text { cultural } \\
\text { changes } & \text { in } & \text { service } \\
\text { delivery } & & \end{array}$ & $\begin{array}{l}\text { - Identify the social and psychological factors that drive or hinder the adoption of } \\
\text { B2B service culture } \\
\text { - Understand how actors garner buy-in and mental commitment from employees and } \\
\text { customers to support service-led operations } \\
\text { - Provide deep and nuanced insights into how cultural, political, psychological, } \\
\text { and/or symbolic factors drive the success or failure of B2B service deliveries } \\
\text { - Identify what kind of communication strategies, artefacts, and symbols managers } \\
\text { employ to cultivate or reinforce service culture in B2B organizations }\end{array}$ \\
\hline Customer engagement & $\begin{array}{l}\text { - Understand how and why CE manifests at individual and organizational levels } \\
\text { - Capture organizational or institutional characteristics that might inhibit (or } \\
\text { amplify) individual CE behaviors } \\
\text { - Reveal when and how CE behaviors at different levels are (mis)aligned } \\
\text { - Understand how and why individuals might change or adapt their CE behaviors in } \\
\text { individual and group settings } \\
\text { - Identify how different social and cultural group dynamics might alter CE behaviors } \\
\text { - Capture how latent or tacit social drivers and cultural inhibitors may influence CE } \\
\text { in different settings }\end{array}$ \\
\hline $\begin{array}{l}\text { Customer experiences } \\
\text { and service journeys }\end{array}$ & $\begin{array}{l}\text { - Capture multiple dimensions of customer experiences simultaneously } \\
\text { - Reveal the differences between different types of service journey } \\
\text { - Understand how customers, as individuals or groups, perceive the lengthy and } \\
\text { complex B2B service delivery processes } \\
\text { - Capture how intra- and inter-organizational social and cultural group dynamics can } \\
\text { - alter customer experiences } \\
\text { - Track when and how individual and group members' customer journeys intertwine } \\
\text { - Uncover the differences and interdependencies between individually and } \\
\text { collectively experienced customer journeys }\end{array}$ \\
\hline
\end{tabular}


Connected technologies and smart services
- Understand how service technologies transform social agents' daily lives, and change their social and cultural behaviors

- Reveal the role different service technologies play in both employees' and customers' daily lives

- Understand how and why different service technologies are utilized (or not) at different stages in the service delivery processes, and what their impacts are on social and cultural interactions

- Discover how and under what conditions specific service technologies add or detract to and from specific customer experiences

\section{Conclusions, implications, and future research avenues}

This article has highlighted the potential opportunities that ethnographic methodologies can offer for B2B service research. Despite their unique strengths and advantages, ethnographic research methods have been relatively overlooked, if not neglected in the contemporary B2B service research (Visconti, 2010; von Koskull, 2014). To remedy the situation, this article advances the argument that ethnography is a highly suitable methodology for B2B service research. Its focus on the lived experiences of individuals in a broader cultural context offers a suite of possible research avenues that can extend our collective understanding of the increasingly complex and expanding notion of B2B service phenomena. This is particularly useful when considering the present need to define and extend critical service constructs such as "actors", "experiences", and "exchange" or "usage processes" (Macdonald et al., 2016). Or when there is a need to understand broad, pervasive and global societal challenges such as how to "better integrate the physical, digital and social realms of services" (Oström et al., 2015; Keating et al., 2018. p .767). Ethnography can also help to unpack the contextual and institutional forces that increasingly shape B2B services.

Several scholars have challenged service researchers to adopt fresh perspectives, and think differently about service theories, priorities, and broader service phenomena (Russell-Bennett, and Baron, 2018; Oström et al., 2015; Brodie and Gustafsson, 2016). This article complements these ideas, and challenges service researchers to think differently about the research methodologies they employ to investigate emerging and contemporary service phenomena. In other words, if the previous studies have provided key goals, frameworks, and roadmaps to advance (B2B) service research, we provide (some of) the tools needed to make this happen, and spotlight (again, some of) the areas which could provide the most fertile ground for applying the ethnographic "toolbox".

For B2B service managers and practitioners, this paper provides important insights on how they could conduct market research and market learning in ways that would provide them more rich, genuine and meaningful customer insights. B2C organizations have a long history of utilizing ethnographic methods to learn more about their customers and usage situations (Cayla and Arnould, 2013), but in the B2B context, leveraging ethnographic methods is relatively rare, if not unheard of. This is surprising, given that B2B services are relatively idiosyncratic, and afford much more room for customer-specific tailoring. Ethnographic approaches could provide B2B service managers with a better understanding of how customers actually (want to) use, evaluate, and experience their services, how the use of those services improves customers' daily (individual and organizational) life, and how they influence the larger service system of which the customer is a part. 
This paper considered the potential of ethnographic methodologies for B2B service research, but did not differentiate between different forms of ethnographic approaches. Future studies could unpack different ethnographic approaches with their distinct strengths and weaknesses, and compare their suitability for specific B2B service areas. Another interesting avenue would be to compare the "common", "best", and "innovative" practices in published ethnographic studies (cf., Piekkari et al., 2010), and consider their suitability for the B2B domain. Finally, from a more practical perspective, future studies could explore whether and how innovative B2B service organizations leverage ethnographic methods to gain deep customer insights.

Looking further to the B2B service research horizon (cf., Keating et al., 2018), there is a growing need for more diverse qualitative research methods to gain a deeper and more holistic understanding of the increasingly complex service phenomenon in contemporary B2B markets. We hope this paper will fuel and encourage scholarly efforts towards more versatile theorybuilding that will enrich and advance future B2B service research.

\section{References}

Arnould, E. J., and Wallendorf, M. (1994), "Market-oriented ethnography: interpretation building and marketing strategy formulation", Journal of marketing research, vol. 31 No. 4, pp. 484-504.

Arnould, E. J., and Price, L. L. (2006), "Market-oriented ethnography revisited. Journal of Advertising Research", Vol. 46 No. 3, pp. 251-262.

Atkinson, P. (2015), For ethnography. Sage.

Borghini, S., Carù, A., and Cova, B. (2010), "Representing BtoB reality in case study research: Challenges and new opportunities“, Industrial Marketing Management, Vol. 39 No. 1, pp. 16-24.

Brax, S. A., and Visintin, F. (2017), "Meta-model of servitization: The integrative profiling approach“, Industrial Marketing Management, Vol. 60, pp.17-32.

Brodie, R. J., Hollebeek, L. D., Jurić, B., and Ilić, A. (2011), “Customer engagement: conceptual domain, fundamental propositions, and implications for research“, Journal of service research, Vol. 14 No. 3, pp. 252-271.

Brodie, R.J., and Gustafsson, A. (2016), "Enhancing theory development in service research, Journal of Service Management, Vol. 27 No. 1, pp. 2-8.

Brodie, R. J., Fehrer, J. A., Jaakkola, E., and Conduit, J. (2018), “Actor Engagement in Networks: Defining the Conceptual Domain“, Journal of Service Research, forthcoming.

Cayla, J., and Arnould, E. (2013), "Ethnographic stories for market learning", Journal of Marketing, Vol. 77 No. 4, pp. 1-16. 
Čaić, M., Odekerken-Schröder, G., and Mahr, D. (2018), "Service robots: value co-creation and co-destruction in elderly care networks“, Journal of Service Management, Vol. 29 No. 2, pp. 178205.

Corbin, J. and Strauss, A.L. (2015), Basics of qualitative research: Techniques and procedures for developing grounded theory, 4rd ed. Newbury Park, CA: Sage.

Cunliffe, A.L. (2010), "Retelling tales of the field: In search of organization ethnography 20 years on”, Organizational Research Methods, Vol. 13 No. 2, pp. 224-239.

Cusumano, M. A., Kahl, S. J., and Suarez, F. F. (2015), "Services, industry evolution, and the competitive strategies of product firms", Strategic Management Journal, Vol. 36 No. 4, pp. 559575.

Elliott, R., and Jankel-Elliott, N. (2003), "Using ethnography in strategic consumer research. Qualitative market research: An international journal”, Vol. 6 No. 4, pp. 215-223.

Fetterman, D. M. (2009), Ethnography: Step-by-step. Applied social research methods series (3rd ed.). Thousand Oaks, CA: Sage Publications Inc.

Gustafsson, A., Högström, C., Radnor, Z., Friman, M., Heinonen, K., Jaakkola, E., and Mele, C. (2016). "Developing service research-paving the way to transdisciplinary research", Journal of Service Management, Vol. 27 No. 1, pp. 9-20.

Hammersley, M., and Atkinson, P. (2007), Ethnography: Principles in practice. Oxford: Routledge.

Hammersley, M. (2013), What's wrong with ethnography? Routledge.

Hoholm, T., and Araujo, L. (2011), "Studying innovation processes in real-time: The promises and challenges of ethnography", Industrial Marketing Management, Vol. 40 No. 6, pp. 933-939.

Huang, M. H., and Rust, R. T. (2018), "Artificial intelligence in service”, Journal of Service Research, Vol. 21 No. 2, pp. 155-172.

Huber, M. and Kleinaltenkamp, M. (2019), “A typology of business usage center members”, Industrial Marketing Management, forthcoming.

Jaakkola, E., and Alexander, M. (2014), "The role of customer engagement behavior in value cocreation: a service system perspective", Journal of service research, Vol. 17 No. 3, pp. 247-261.

Jaakkola, E., Helkkula, A., and Aarikka-Stenroos, L. (2015), "Understanding and advancing service experience co-creation”, Journal of Service Management, Vol. 26 No. 2.

Jaakkola, E., Conduit, J., and Fehrer, J.A. (2018), Tracking the Evolution of Engagement Research: Illustration of Midrange Theory in the Service Dominant Paradigm, in Sage Handbook of Service-Dominant Logic, Robert F. Lusch and Stephen L. Vargo, eds. London: Sage, 580-598. 
Katz, J. (2001), "From how to why: On luminous description and causal inference in ethnography (Part I)", Ethnography, Vol. 2 No. 4, pp. 443-473.

Keating, B. W., McColl-Kennedy, J. R., and Solnet, D. (2018), "Theorizing beyond the horizon: service research in 2050", Journal of Service Management, Vol. 29 No. 5, pp. 766-775.

Kleinaltenkamp, M., Plewa, C., Gudergan, S., Karpen, I. O., and Chen, T. (2017), "Usage centervalue cocreation in multi-actor usage processes", Journal of Service Theory and Practice, Vol. 27 No. 4, pp. 721-737.

Koro-Ljungberg, M., and Greckhamer, T. (2005), “Strategic turns labeled 'ethnography': From description to openly ideological production of cultures" Qualitative research, Vol. 5 No. 3, pp. 285-306.

Kowalkowski, C., Gebauer, H., and Oliva, R. (2017), "Service growth in product firms: Past, present, and future", Industrial marketing management, Vol. 60, pp. 82-88.

Kunz, W.H., Heinonen, K., and Lemmink, J. (2019), "Future Service Technologies - Is Service Research on Track with Business Reality?", Journal of Services Marketing, Vol. 33, forthcoming.

La Rocca, A., Hoholm, T., and Mørk, B. E. (2017), "Practice theory and the study of interaction in business relationships: Some methodological implications", Industrial Marketing Management, Vol. 60, pp. 187-195.

Lemon, K. N., and Verhoef, P. C. (2016), "Understanding customer experience throughout the customer journey”, Journal of marketing, Vol. 80 No. 6, pp. 69-96.

Lusch, R. F., Vargo, S. L., and Gustafsson, A. (2016), "Fostering a trans-disciplinary perspectives of service ecosystems”, Journal of Business Research, Vol. 69 No. 8, pp. 2957-2963.

Mannay, D., and Morgan, M. (2015), "Doing ethnography or applying a qualitative technique? Reflections from the 'waiting field”. Qualitative Research, Vol. 15 No. 2, pp. 166-182.

Macdonald, E. K., Kleinaltenkamp, M., and Wilson, H. N. (2016), "How business customers judge solutions: Solution quality and value in use", Journal of Marketing, Vol. 80 No. 3, pp. 96-120.

McColl-Kennedy, J. R., Gustafsson, A., Jaakkola, E., Klaus, P., Radnor, Z. J., Perks, H., and Friman, M. (2015), "Fresh perspectives on customer experience", Journal of Services Marketing, Vol. 29 No 6/7, pp. 430-435.

Ostrom, A. L., Bitner, M. J., Brown, S. W., Burkhard, K. A., Goul, M., Smith-Daniels, V., ... and Rabinovich, E. (2010), "Moving forward and making a difference: research priorities for the science of service", Journal of service research, Vol. 13 No. 1, pp. 4-36.

Ostrom, A. L., Parasuraman, A., Bowen, D. E., Patricio, L., and Voss, C. A. (2015), "Service research priorities in a rapidly changing context", Journal of Service Research, Vol. 18 No. 2, pp. 127-159.

Pettigrew, S. F. (2000), Ethnography and grounded theory: a happy marriage? ACR North American Advances. 
Piekkari, R., Plakoyiannaki, E., and Welch, C. (2010), “Good'case research in industrial marketing: insights from research practice", Industrial Marketing Management, Vol. 39 No. 1, pp. 109-117.

Porter, M. E., and Heppelmann, J. E. (2014), "How smart, connected products are transforming competition", Harvard business review, Vol. 92 No. 11, pp. 64-88.

Pressey, A. D., Gilchrist, A. J., \& Lenney, P. (2014), "Sales and marketing resistance to key account management implementation: An ethnographic investigation", Industrial Marketing Management, Vol. 43 No. 7, pp. 1157-1171.

Prior, D. D. (2016), "Boundary spanning and customer service styles in business solutions implementation”, Industrial Marketing Management, Vol. 59, pp. 120-129.

Prior, D. D., Keränen, J., and Koskela, S. (2019), "Customer participation antecedents, profiles and value-in-use goals in complex B2B service exchange", Industrial Marketing Management, forthcoming

Reinartz, W. J., and Berkmann, M. (2018), "From customer to partner engagement: a conceptualization and typology of engagement in B2B", In Customer engagement marketing (pp. 243-268). Palgrave Macmillan, Cham.

Rouleau, L., De Rond, M., and Musca, G. (2014), "From the ethnographic turn to new forms of organizational ethnography", Journal of Organizational Ethnography, Vol. 3 No. 1, pp. 2-9.

Russell-Bennett, R., and Baron, S. (2015), "Fresh thinking in services marketing: contemporary, cutting-edge and creative thoughts", Journal of Services Marketing, Vol. 29 No. 6/7, pp. 421-424.

Sharma, P., Tam, J., and Wu, Z. (2018), "Challenges and opportunities for services marketers in a culturally diverse global marketplace”, Journal of Services Marketing, Vol. 32 No. 5, pp. 521529.

Strudwick, R. (2018), “Tensions in ethnographic observation: overt or covert? Journal of Organizational Ethnography.

Tuli, K. R., Kohli, A. K., and Bharadwaj, S. G. (2007), "Rethinking customer solutions: From product bundles to relational processes", Journal of marketing, Vol. 71 No. 3, pp. 1-17.

Töytäri, P., Keränen, J., and Rajala, R. (2017), "Barriers to implementing value-based pricing in industrial markets: A micro-foundations perspective", Journal of Business Research, Vol. 76, pp. 237-246.

Ulaga, W., and Loveland, J. M. (2014), "Transitioning from product to service-led growth in manufacturing firms: Emergent challenges in selecting and managing the industrial sales force", Industrial Marketing Management, Vol. 43 No. 1, pp. 113-125.

Ulaga, W., and Reinartz, W. J. (2011), "Hybrid offerings: how manufacturing firms combine goods and services successfully", Journal of marketing, Vol. 75 No. 6, pp. 5-23. 
Ulaga, W. (2018), “The journey towards customer centricity and service growth in B2B: a commentary and research directions", AMS Review, Vol. 8 No. 1-2, pp. 80-83.

Van Doorn, J., Lemon, K. N., Mittal, V., Nass, S., Pick, D., Pirner, P., \& Verhoef, P. C. (2010), "Customer engagement behavior: theoretical foundations and research directions", Journal of service research, Vol. 13 No. 3, pp. 253-266.

Van Doorn, J., Mende, M., Noble, S. M., Hulland, J., Ostrom, A. L., Grewal, D., and Petersen, J. A. (2017), "Domo arigato Mr. Roboto: Emergence of automated social presence in organizational frontlines and customers' service experiences", Journal of Service Research, Vol. 20, No. 1, pp. 43-58.

van Maanen, J. (1988), Tales of the field: On writing ethnography. Chicago: University of Chicago Press.

Van Maanen, J. (2006), "Ethnography then and now", Qualitative Research in Organizations and Management: An International Journal, Vol. 1 No. 1, pp.13-21,

Visconti, L. M. (2010), "Ethnographic Case Study (ECS): Abductive modeling of ethnography and improving the relevance in business marketing research", Industrial Marketing Management, Vol. 39, No. 1, pp. 25-39.

Vivek, S. D., Dalela, V., and Beatty, S. E. (2016), "Partner engagement: a perspective on B2B engagement", In Customer Engagement (pp. 71-84). Routledge.

von Koskull, C. (2014), "Ethnographic Research in Service Marketing: Theory, Methods, and Practice"; In Field Guide to Case Study Research in Business-to-business Marketing and Purchasing (pp. 101-145). Emerald Group Publishing Limited.

Wirtz, J., Patterson, P. G., Kunz, W. H., Gruber, T., Lu, V. N., Paluch, S., and Martins, A. (2018), "Brave new world: service robots in the frontline", Journal of Service Management, Vol. 29 No. 5, pp. 907-931.

Wünderlich, N. V., Heinonen, K., Ostrom, A. L., Patricio, L., Sousa, R., Voss, C., and Lemmink, J. G. (2015), “'Futurizing' smart service: implications for service researchers and managers. Journal of Services Marketing”, Vol 29, No 6/7, pp. 442-447.

Yin, R. (2016), Case study research, $6^{\text {th }}$ edition. Beverly Hills: Sage Publications.

Zilber, T.B. (2014), "Beyond a single organization: Challenges and opportunities in doing field level ethnography”, Journal of Organizational Ethnography, Vol.3 No. 1, pp. 96-113.

Zolkiewski, J., Story, V., Burton, J., Chan, P., Gomes, A., Hunter-Jones, P. ... and Robinson, W. (2017), "Strategic B2B customer experience management: the importance of outcomes-based measures”, Journal of Services Marketing, Vol. 31 No. 2, pp. 172-184. 